\title{
Pre-print
}

\section{Analysis of the efficiency of wind turbine gearboxes using the temperature variable}

\author{
Sequeira, C. ${ }^{*}$, Pacheco, A. ${ }^{1}$, Galego, Pedro M. ${ }^{2}$, Gorbeña, E. ${ }^{1}$ \\ ${ }^{1}$ MORE-CIMA/Universidade do Algarve, Edifício 7, Campus de Gambelas Faro, 8005-139, Portugal, \\ cdsequeira@ualg.pt, ampacheco@ualg.pt, egeisenmann@ualg.pt \\ ${ }^{2}$ Instituto Superior de Engenharia, Universidade do Algarve, Campus da Penha, 8005-139 Portugal, \\ pedromiguelgalego@hotmail.com
}

Doi: https://doi.org/10.1016/j.renene.2018.12.040

\begin{abstract}
The aim of this paper is to evaluate how lubricant selection affects gearbox efficiency and overall energy production by analysing real data from wind farms, monitored and controlled by a Supervisory Control and Data Acquisition (SCADA system). The turbines analysed worked with two or more oil types for the same amount of hours, which allowed to establish relations between the active power curves and wind velocity; oil temperature inside gearboxes and wind velocity; and oil temperature inside gearboxes and active power production. The results of this study evidenced a direct relation between oil characteristics and energy efficiency i.e. gearboxes working with mineral oil perform better then gearboxes working with synthetic oils. Those differences can be significant in terms of active power production. Also, it was observed oil degradation as function of temperature increase, with changes on viscosity, which reveals that temperature behaviour along the active power curve is strongly related to oil' characteristics.
\end{abstract}

Keywords: Wind Turbine, Gearbox, Oil temperature, SCADA 


\section{Pre-print}

\section{Introduction}

The rapid growth in wind power needs fast improvements in technology. Up until now, the industry has seen steady growth and it can be expected that growth show similartrend in the future. The market forecasts that by 2018 the wind energy cumulative gigawatts (GW) will be $43 \%$ higher than of 2015 's GW [1]. Given these numbers and the high initial investment needed to build a wind farm, we ask ourselves: "Can we not produce more energy with the same amount of wind turbines?"; "it is possible to increase the efficiency and performance of each wind turbine within an existent wind farm?"

Monitoring the state of any industrial process is nowadays an indispensable tool. Early failure detection prevents major faults from occurring, allowing operation and maintenance departments to have accurate information about the machine's operating state. Also, performance improvement is significant when there are efficient maintenance and adequate repair strategies. It is today acknowledge that improvement of the operations and maintenance (O\&M) practices can lead to a reduction of $21 \%$ and $11 \%$ of the life-cycle costs of offshore and inland wind farms [2]. Therefore, studies of novel methods serving the wind farm O\&M procedures are extremely important and valuable. With the development of technology wind turbines have increased in size. Consequently, this has also led to a situation where components failures result in high costs. The most important components, which will define the effective production of energy from a wind turbine, are the gearbox and electrical generator. Wind turbine gearboxes handle several megawatt of power, which means that a small efficiency increase can produce energy useful for several more households [3]. Thus, to make wind energy competitive is fundamental to increase gearbox efficiency, availability and reliability, for which is important to quantify the main sources of power loss. Lubrication is a significant issue in gearbox operation since the main power losses sources are friction loss between the meshing teeth [4-6]. As such, monitoring the gearbox oil temperature can be the most effective way to reduce the operational and maintenance costs of these systems and increase their reliability. With good data acquisition (i.e. vibrations and temperature) faults can be detected while components are operating which can lead to the implementation of appropriate and timely actions to prevent damage or failure of the turbine' components [7]. 
Moreover, in order to reduce friction it is fundamental the oil selection to minimize wear on the gear teeth and bearings, allowing optimized behaviour under the external environmental conditions in which the turbine will operate [8]. As such, the selection of a lubricant with appropriate physical properties promotes small no-load losses, which also contributes to decrease the lubricant operating temperature [3,9]. No-load losses are directly related to lubricant viscosity and density, as well as immersion depth of the components on a sump-lubricated gearbox; while no-load rolling bearing losses depends on type and size, arrangement, lubricant viscosity and immersion depth [4]. In addition, transmission losses are primarily due to viscous friction of the gears and bearings turning in oil [10].

Intermittent operation, a common situation with wind turbines, can also have a significant impact on the life of a gearbox. When the turbine is not running, oil may drain away from the gears and bearings, resulting in insufficient lubrication when the turbine starts [1012]. As well, under cold weather, the oil may have too high viscosity until the gearbox has warmed up. Turbines in such environments may benefit by having gearbox oil heaters since condensation of moisture may accelerate corrosion [13-17]. Over the last 2 decades many lessons have been learnt by the industry with the main goal of improving gearboxes reliability, since is one of the most expensive wind turbine sub-assemblies [18-23].

The gearbox reached thermal equilibrium when the operating temperature stabilizes, i.e. when the power dissipated inside the gearbox is equal to the heat evacuated from gearbox to the nacelle. The equilibrium temperature is dependent of the gearbox characteristics and of the lubricant properties. A lower stabilization temperature means higher efficiency, lower friction coefficient, smaller oil oxidation and longer oil life [24-25].

In general, and for wind industry practitioners, it is important to pay great attention to data farming issues. This means that more precise fault definition and more advanced fault-labelling systems need to be developed so that more informative and useful data can be collected. As result, producers will have access to better and more accurate diagnoses to evaluate the health status of their machines and it productivity [26]. The present paper is focus on the analysis of real data from 12 different wind farms, which are monitored and controlled by a Supervisory Control and Data Acquisition - the SCADA system. The system is composed 93 by sensors or actuators that enable the monitoring and control of geographically dispersed processes. It also allows communication between remote 


\section{Pre-print}

stations and a control centre, providing important data and information for controlling the operating process of the power electrical system. The occurrence of disturbances triggers alarms, which warn operators that the system is in an anomalous situation, permitting operators to intervene from the control centre. The SCADA data analysis methods has been used recently to assess the importance of how wind turbines align in patterns to the wind direction. Revealing itself as useful tool to evaluate wake effects in a wind farm [27]. In present study, the SCADA data is analysed to assess the influence of the oil formulation on energy production, by analysing oil temperatures inside gearboxes (i.e. oil sump). The aim of the paper is to evaluate how lubricant selection affects gearbox efficiency, and it influence on energy production losses.

\section{Methods}

Gearbox oil pressure and oil filter status are related to the gearbox oil pump, the pressure, temperature and lubrication filters. Since temperature is a fundamental parameter in the dynamic behaviour of the oil, conditioning gearbox efficiency and overall wind turbine performance, the SCADA system is programmed to acquire data every 10 minutes of the following parameters: outdoor temperature, temperature of the nacelle, main bearing temperature, gearbox bearing temperature and gearbox oil temperature. The optimum temperature for gearbox oil ranges between $45^{\circ} \mathrm{C}$ and $65^{\circ} \mathrm{C}$. This optimum is ensured by the cooling system (Figure 1). The temperature sensors work as follows: (i) if the temperature at the opening of the thermostatic valve is $\sim 45^{\circ} \mathrm{C}$ the oil circulates through the heat exchangers, but the fans are not working; (ii) if temperature reaches $62^{\circ} \mathrm{C}$ both fans of the two exchangers start working; (iii) the fans will turn off when the temperature falls $5^{\circ} \mathrm{C}$ (i.e. $57^{\circ} \mathrm{C}$ at the opening of the thermostatic valve); (iv) the temperature to drive the 2 nd 120 speed of the mechanical pump is $58^{\circ} \mathrm{C}$; and (v) the 2 nd 121 pump shuts off when oil temperature reaches again the $48^{\circ} \mathrm{C}$. Periodic oil samples are collected on wind turbine gearboxes (i.e. every six months) to assess the state of the oil, as well as to check for signs of internal wear. Thus, if a value is over a certain maximum, the sampling strategy is changed to monitor a given component preventing it failure.

Data such as rotational speed, power output, temperature 126 and efficiency from the last 6 years was analysed in which regards oil changes and its effect on performance. The three types of oils (A, B and C, hereafter) are within the same viscosity grade (e.g. ISO 


\section{Pre-print}

VG 320), and expected to have a viscosity of $\sim 320 \mathrm{cSt}$ at $40^{\circ} \mathrm{C}$ (Table 1 ). In order to compare the influence of using different oils inside gearboxes, the SCADA data was first filter to select turbines which: (1) worked with more than 1 or 2 types of oils inside the gearbox; (2) the same amount of working hours; and (3) never had it gearbox replaced. After these restrictions, the sample data reports to four wind turbines located in the Freita Wind Park, North of Portugal (Figure 2, Table 2). The park has 18.4 MW of installed power distributed for 8 Nordex N90/2300 turbines and is property of Iberwind (www.iberwind.com). The annual estimated energy production of these devices is 40 GWh, traducing on a reduction of 26.637 ton $\mathrm{CO} 2$ emissions. The collected data was cleaned to ensure that only data obtained during normal operation of the turbine was used i.e. values were excluded from the database under the following circumstances: (1) wind speed is out of the operating range; (2) wind turbine cannot operate because of a fault condition; and (3) turbine is manually shut down or in a test or maintenance operating mode. The filtered datasets were than analysed to evaluate wind energy production efficiency depending of the type of oil used for different periods, applying bins method [28]. The method is a data reduction procedure that groups test data for a certain parameter into wind speed intervals (bins). These interval values are created on the $\mathrm{x}$ axis, y-axis, or both axis (e.g. wind speed versus oil temperature; oil temperature versus active power), by calculating the mean of these intervals for both $\mathrm{x}$ and $\mathrm{y}$ values. For each bin the number of data sets or samples and their sum are recorded, and the average parameter value within each bin is calculated. In particular, the mean values of the normalized wind speed, gearbox oil temperature and active power were determined using interval bins of $0.5 \mathrm{~m} / \mathrm{s}, 1^{\circ} \mathrm{C}$ and $1 \mathrm{~kW}$, respectively.

\section{Results}

Figure 3 shows the oil temperatures changes as function of wind speed for the three analysed oil types before applying the bin method. It can be observed the high number of observations from the SCADA dataset before applying the bin method. Figure 4 shows the results of the bin method for the four analysed wind turbine gearboxes (Wtg) and for the three different oil types (Table 1) i.e. active 159 power curves as a function of velocity (A); oil temperature inside gearboxes as a function of velocity (B); and oil temperature inside gearboxes as a function of active power production (C). As it can be observed, 


\section{Pre-print}

several changes occur on each pair of analyse parameters: as the wind turbine rotate different powers curve are obtained using different oils types (Figure 4A), affecting temperature inside the gearbox which tend to increase as turbine spins faster (Figure 4B). The best lubricant supply is when the gear mesh achieve the lower temperature (Figure $4 C)$.

In general, what Figure 4 shows is that for the same wind turbine at the same velocity there are different power/efficiency behaviours with similar oil types (B and C, both synthetic) and between an oil of different nature (type A, mineral). For a more detail analysis of the results, each turbine is then analysed independently having into consideration the type of oil and number of oil changes at the four wind turbine gearboxes (Table 2). This is done because two turbines had two oil changes (i.e. Wtg\#3, Wtg\#7), while the other two (i.e. $\mathrm{Wtg} \# 4, \mathrm{Wtg} \# 6$ ) were subjected to an additional one.

On Figure 5A it can be observed significant differences in the use of different types of oils on wind turbine gearbox 3 (Wtg\#3). The gearbox oil was changed from type A to C i.e. mineral to synthetic. For the same wind turbine input speed, type $\mathrm{C}$ (synthetic) oil achieves higher temperatures than type A (mineral). The greatest differences in temperature are recorded within velocity range 5 to $12 \mathrm{~m} / \mathrm{s}$ (Figure 5B). This corresponds to the beginning of the turbine's power curve, for which relates the largest number of observations. Analysing the active power produced in the higher temperature range (Figure 5C), i.e. between $50^{\circ} \mathrm{C}$ and $64^{\circ} \mathrm{C}$, is observed that at an oil temperature of $58^{\circ} \mathrm{C}$, gearbox with type $\mathrm{C}$ produces $1700 \mathrm{~kW}$, while type A records approximately $1900 \mathrm{~kW}$. It is also observed that, since the bins are " $1^{\circ} \mathrm{C}$ ", the range of values between 57 and $59^{\circ}$ $\mathrm{C}$ corresponds to the highest number of observations i.e. approximately 5700 data for $2000 \mathrm{~kW}$ of recorded power. Figure 5D shows differences of wind energy production within the range of speeds between 12 and $15 \mathrm{~m} / \mathrm{s}$, since the largest differences are within this range. It is observed that for an input velocity of $14 \mathrm{~m} / \mathrm{s}$, power differences between oil types are close to $20 \mathrm{~kW}$.

The gearbox of turbine number 4 (Wtg\#4, Figure 6) experienced three different oils types. Observing Figure 6A, it is possible to verify significant differences in temperature for the same input speed. Again, oil type $\mathrm{C}$ registered the higher temperatures confirming the results 192 obtained in turbine 3. Also, it is within the velocity range between 5 and 12 $\mathrm{m} / \mathrm{s}$ that the largest temperature differences are recorded (Figure 6B), which corresponds 


\section{Pre-print}

to the largest number of observations. All registers are found to be above $45^{\circ} \mathrm{C}$, which means that the oil is circulating in the heat exchanger and fans are not working. The data also shows large differences in temperature at low speeds, reaching a maximum of $8^{\circ} \mathrm{C}$ difference between two types of synthetic oils from different suppliers. Analysing the active power produced in the higher temperature range (Figure $6 \mathrm{C}$ ), i.e. between $50^{\circ} \mathrm{C}$ and $62^{\circ} \mathrm{C}$, results differ from turbine 3 . At $54^{\circ} \mathrm{C}$ large differences in production can be observed between the three types, but with increasing temperatures, those differences disappear (i.e. $56.5^{\circ} \mathrm{C}$ bin). However, the continuous increase of temperature after this point leads again to changes on active power production, with deficits of $150 \mathrm{~kW}$ between oil type $\mathrm{C}$ and $\mathrm{B}$ and $200 \mathrm{~kW}$ between $\mathrm{C}$ and $\mathrm{A}$, confirming that $\mathrm{C}$ type oil adversely affects energy production. The active power difference is then analysed within the 12 and $24 \mathrm{~m} / \mathrm{s}$ range (Figure 6D) where is observed that oil B presents the worst behaviour. This is particular evident for velocities over $19 \mathrm{~m} / \mathrm{s}$, despite presenting lower temperatures inside gearbox than type $\mathrm{C}$. The major differences between type $\mathrm{A}$ and $\mathrm{C}$ on active power production are recorded around $\sim 18 \mathrm{~m} / \mathrm{s}$ ( $\sim 40 \mathrm{~kW}$ difference), with type A registering better behaviour. However, at the maximum load area (i.e. input velocity $\sim 20 \mathrm{~m} / \mathrm{s}$ ), the two oils present a very similar performance.

The gearbox of turbine number 6 (Wtg\#6, Figure 7) also experienced three different oils types. Observing Figure 7A it is possible to verify significant differences in temperature for the same input wind velocity. But this time, on contrary to turbine 4, type A presents the higher temperatures inside gearbox for velocities over $10 \mathrm{~m} / \mathrm{s}$ i.e. the beginning of nominal wind speed. For lower velocities type $\mathrm{C}$ presents higher temperatures (Figure 7B). The largest production differences are recorded in the temperature range between $52^{\circ} \mathrm{C}$ and $56^{\circ} \mathrm{C}$ i.e. before the exchanger fans are turned on. For example, for a production of $1500 \mathrm{~kW}$, type $\mathrm{B}$ oil registers $52.5^{\circ} \mathrm{C}$, type $\mathrm{C} \sim 54^{\circ} \mathrm{C}$ and type $\mathrm{A} \sim 56^{\circ} \mathrm{C}$ (Figure $7 \mathrm{C}$ ). The oil temperature increase at $\sim 58.5^{\circ} \mathrm{C}$ shows a production difference of $500 \mathrm{~kW}$, comparing oils type A and B; whereas differences between types A and C are $\sim 50 \mathrm{~kW}$. When analysing the active power difference within the 12 and $24 \mathrm{~m} / \mathrm{s}$ range (Figure 7D) it can be observed that oil B presents again the worst overall behaviour.

Again, a very similar performance to Wtg\#4 is registered 224 by comparing type A and $\mathrm{C}$ oils at the maximum load area of the turbine (i.e. $20 \mathrm{~m} / \mathrm{s}$ ). The gearbox of turbine 7 experienced the use of two oils as turbine 3 (Figure 8). However, on the contrary of 


\section{Pre-print}

\section{6}

turbine 3, type A achieves higher temperatures (Figure 8A), although those differences are only noticeable over $9 \mathrm{~m} / \mathrm{s}$ (Figure $8 \mathrm{~B}$ ). In terms of production, the largest differences were recorded between $52^{\circ} \mathrm{C}$ and $57^{\circ} \mathrm{C}$ i.e. before the exchanger fans are turned on. For example, for a production of $1500 \mathrm{~kW}$, oil type $\mathrm{C}$ registers $56^{\circ} \mathrm{C}$, while type A oil registers $56,2^{\circ} \mathrm{C}$. Highest differences of $\sim 1^{\circ} \mathrm{C}$ are observed at $1000 \mathrm{~kW}$. The increase of oil temperature over $\sim 60^{\circ} \mathrm{C}$ has negligible effect on production. It is within the 12 and 24 $\mathrm{m} / \mathrm{s}$ range that highest differences are recorded on active power production, registering a maximum of plus $80 \mathrm{~kW}$ using type A oil at $18.2 \mathrm{~m} / \mathrm{s}$. But, overall, it is observed a very random behaviour between the two types. Once more, a very similar performance is registered at the maximum load area of the turbine (i.e. $20 \mathrm{~m} / \mathrm{s}$ ).

The analyses of oil samples collected on the different gearboxes confirm the above results (Table 3). The reference values of viscosity at $40^{\circ} \mathrm{C}$ (Table 1 ) for the three analysed oils are $320 \mathrm{cSt}$ (type A), $320 \mathrm{cSt}$ (type B) and $325 \mathrm{cSt}$ (type C). Table 3 shows oil viscosity analysis after use, where it can be observed that the main changes on viscosity occur for type B and C oils. A maximum drop from 320 to $306.93 \mathrm{cSt}$ is verified in oil type B on turbine 4. Because oil type A registers, in general, lower temperatures, it positively influences the non-change of viscosity at $40^{\circ} \mathrm{C}$.

The analysis of viscosity at $100^{\circ} \mathrm{C}$ reveals similar trends. The reference values of viscosity at $100^{\circ} \mathrm{C}$ (Table 1) for the three analysed oils are $24.1 \mathrm{cSt}$ (type A), $35.1 \mathrm{cSt}$ (type B) and $34.9 \mathrm{cSt}$ (type C). Again, oil types B and C show increase degradation, with maximum changes occurring once again on type B oil, dropping from 35.1 to $31.38 \mathrm{cSt}$ on turbine 6 . Turbine 4 using type B oil also show a significant decrease (e.g. drop to $32.14 \mathrm{cSt}$ ). Gearboxes using type $\mathrm{C}$ oil also show average decreases in the order of $3 \mathrm{cSt}$ for all the turbines, except in turbine 7 . However, turbine 7 was the one registering smaller differences of temperatures within all power operation range, but also smaller active power productions. Finally, the reference values of viscosity index (ASTM D 2270, Table 1) for the three analysed oils are 96 (type A), 155 (type B) and 152 (type C). Major changes occur on gearbox of turbine 4 (Table 3) when using type B oil (drop from 155 to 145) and type C oil (dr 256 op from 152 to 147). Negligible variations are showed on gearboxes using type A oil. 


\section{Pre-print}

\section{Discussion}

Conditioning monitoring of gearbox systems is essential for mechanical system reliability management [29]. The today use of control systems such as SCADA able the access to a large amount of real time sensor data that can be used to prevent turbine failures and loss of efficiencies. Wind industry has been attempting to integrate SCADA and Conditioning Monitoring Systems (CMS) data to detect, diagnose and predict gearbox failures [30]. In that sense, oil and lubrication analysis is one among many important conditionmonitoring approaches. Oil cleanness, viscosity and temperature give insight onto how the gearbox of any wind turbine is performing [31].

As an example, the today understanding of the mechanisms involved in pitting damage is still incomplete. This is partly due to large number of influencing factors that must be taken into account when studying Rolling Contact Fatigue. Indeed, literature underlines the impact of tribological parameters (loading, contact conditions and lubricant viscosity [32]) together with material parameters (steel composition, thermo-chemical treatment, surface roughness and residual stresses) and environmental parameters (temperature, humidity and lubricant chemistry [33]). But, amongst all these parameters, it is today well known that lubrication has a significant influence on Rolling Contact Fatigue and on pitting, in particular [34].

The results presented within this study are based on relations established between the active power curves and wind velocity; oil temperature inside gearboxes and wind velocity; and oil temperature inside gearboxes and active power production. The propose was to analyse how lubricant selection affects gearbox efficiency and overall energy production by analysing real data from wind farms.

Overall, results show that, most of the time, the temperature of mineral oil (type A) was lower than synthetic type oils (type B and C) for the same input velocities. Moreover, gearboxes working with type A oil performed better than gearboxes with type B or C oils. In some cases, performance differences achieved maximum of $200 \mathrm{~kW}$ in active production (e.g. \#Wtg3 at $50^{\circ} \mathrm{C}$, Figure 4 between Type $\mathrm{A}$ and $\mathrm{C}$ oils). There is a direct relation between oil quality inside gearboxes with energy efficiency. A maximum viscosity drop from 320 to $306.93 \mathrm{cSt}$ was verified 288 in oil type B on turbine number 4. Also, it is within the velocity range between 5 and $12 \mathrm{~m} / \mathrm{s}$ that the largest temperature differences are recorded (Figure 6B), which corresponds to the largest number of 


\section{Pre-print}

observations, meaning that this particular turbine has worked most of the time within this velocity range.

This is an important result since the most common gear failures (e.g. wear, scuffing, micropitting, pitting, etc) are influenced by the oil temperature in the lubrication system [35]. As a direct result of viscosity and additives decrease, several studies recorded pitting initiation, suggesting that lubricant additives can promote crack initiation by creating corrosion pits on steel surfaces [36, 37]. This because high temperatures are linked with a decrease of oil viscosity, producing thin lubricant films in the gear mesh which can affect performance. For example, the formation of a tribofilm from Zinc Dialkyl Dithio Phosphate (ZDDP), an anti-wear additive, can also promote crack initiation by preventing surfaces roughness reduction during running-in [38].

Higher temperatures can also lead to higher stress on the material composing the gearbox system e.g. for gear oils with additives higher temperatures correspond with higher chemical activity [35]. As an example, Nutakor et al [39] studied how the design parameters of planetary gear sets, bearings and lubricant properties influence the wind turbine performance. The authors concluded that decreasing oil viscosity by increasing oil temperature results in significant increase of bearing mechanical power losses inside of the gearbox on a planetary gear.

A gearbox is the component with more operational complexity and unit cost [40] and therefore vibration data and oil condition data has been used as the main input in behavioural models, neural networks, finite element modelling and statistical methods to predict gearbox failures. As an example, an approach for utilization of SCADA data for conditioning monitoring by means of artificial neural networks (ANN) was recently developed [41]. The approach was based on creating normal behaviour models for critical components by closely monitoring gearbox oil temperature, enabling to detect anomalous operations.

The present paper results add to the literature by presenting a clear case study of the relation between oil temperature and viscosity inside gearboxes with energy efficiency, which can be further use on ANN training to detect and prevent gearbox failures and optimize oil changing procedures. What appears clear from the results is that oil characteristics play a significant role on efficiency 321 losses, strongly highlighted by the analysis of gearboxes that experienced the usage of the three different oil types. It is also 


\section{Pre-print}

evident that mineral type A presents better performance than synthetic B and C types. An interesting fact is that although type B shows lower temperatures than type $\mathrm{A}$, there is no positive effect on production. In fact, gearboxes working with oil type B show a drop on production between the 12 and $24 \mathrm{~m} / \mathrm{s}$ range (e.g. \#Wtg4, Figure 6). This type B oil is currently being withdrawn by the promotor from several turbines of different wind farms due to it poor performance; and because of the change in the viscosity index after 1 year of operation. The type $\mathrm{C}$ oil is the one presenting worse results, both in terms of temperature and active power production. This is a general trend at all the turbines that use this oil on their gearbox.

Another interesting aspect relates with the behavioural of the temperature using different oil types along the active power curve. Within the maximum turbine load area, comprised between the achievement of the rated output and cut-off speeds (i.e. wind over $\sim 14 \mathrm{~m} / \mathrm{s}$ ), type $\mathrm{A}$ and $\mathrm{C}$ register a very similar behaviour. In fact, and observing gearbox of turbine 6 (\#Wtg6, Figure 7) working with oil type A, higher temperatures are recorded, which adversely affects performance. However, this result is not pronounced and is particular to this area of the power curve, restricted to fewer observations when compared to the data collected between the cut-in and rated power speed curve area, where type A oils always performs better.

Finally, the papers shows the capability of the proposed method on identifying different out-put power behaviours linked to oil temperature; and how to identify possible failures through temperature patterns. Oil temperature indicator can be used as a complement in Condition Monitoring Systems (CMS), which have been primarily focused on measuring the particle contamination in the lubricant fluid [42]. The close monitoring of this parameter by O\&M managers will allow then to have sufficient time to plan up-tower repairs, by enabling them to reduce downtime, heavy equipment and logistics costs and, most important, preventing consequential failures in the entire gearbox system.

\section{Conclusions}

This paper analysed time-series of active power production and it relation to oil temperature inside gearboxes using SCADA 354 data, supported by regular viscosity oil analysis. The main conclusion from the result analysis are: (i) temperature inside gearboxes working with mineral oils were lower than synthetic oil types; (ii) there is a 


\section{Pre-print}

direct relation between oil characteristics and energy efficiency i.e. gearboxes working with mineral oil perform better then gearboxes working with synthetic oils. Those differences are significant, achieving maximums of $200 \mathrm{~kW}$ differences on active power production; (iii) oils of similar nature (i.e. synthetic) present significant differences on performance, and even oils that resist to a temperature increase can show worst performance on active power production; and (iv) finally, degradation of oil was influenced by the temperature rise and viscosity decrease, showing that temperature behaviour along the active power curve is strongly related to oil type characteristics.

The close monitoring of these parameters inside the gearbox reveal vital in order to evaluate performance drops and can be used to detect mechanical faults as well as to extend the lifetime of the components. In order to increase the gearbox reliability it would be necessary to complement the above analysis with the study of the particle count (i.e. oil debris) and evaluate it effect on the overall energy production.

\section{Notation}

Toil - oil sump temperature $\left({ }^{\circ} \mathrm{C}\right)$

\section{Acknowledgements}

The paper is a contribution to the SCORE project, funded by the Portuguese Foundation for Science and Technology (FCT - PTDC/AAG-TEC/1710/2014) and MONITOR project, funded by the Atlantic Area (EAPA_333/2016). André Pacheco was supported by the Portuguese Foundation for Science and Technology under the Portuguese Researchers' Programme 2014 entitled "Exploring new concepts for extracting energy from tides" (IF/00286/2014/CP1234). Eduardo G-Gorbeña has received funding for the OpTiCA project from the Marie Skłodowska-Curie Actions of the European Union's H2020-MSCA-IF-EF-RI-2016 / under REA grant agreement $n^{\circ}$ [748747]. The authors acknowledge IberWind for supplying all data measurements. 


\section{Pre-print}

\section{References}

[1] WWEA - World Wind Energy Association, "WWEA half-year report: world wind capacity reached $456 \mathrm{GW}, " 10$ Outubro 2016. [Online]. Available: http://www.wwindea.org/. [Accessed 15.12.2017].

[2] Sheng, S. Prognostics and Health Management of Wind Turbines: Current Status and Future Opportunities, National Renewable Energy Laboratory, Golden, CO; 2015. https://www.nrel.gov/docs/fy16osti/65605.pdf [Accessed 31.08.2018].

[3] Fernandes, C. M., Blazquez, L., Sanesteban, J., Martins, R., Seabra, J. Energy efficiency tests in a full scale wind turbine gearbox. Tribology International, 2016. https://doi.org/10.1016/j.triboint.2016.05.001

[4] Fernandes CM., Marques PM., Martins RC., Seabra JH. Gearbox power loss. Part III: application to a parallel axis and a planetary gearbox. Tribol Int 2015;88 (0):31726. http://dx.doi.org/10.1016/j.triboint.2015.03.029

[5] Marques, P.M., Camacho, R., Martins R.C., Seabra, J.H. Efficiency of a planetary multiplier gearbox: Influence of operating conditions and gear oil formulation.

Tribology International 2015; 92: 272-280.

https://doi.org/10.1016/j.triboint.2015.06.018

[6] Wang, Y., Song, G., Niu, W., Chen, Y. Influence of oil injection methods on the lubrication process of high speed spur gears. Tribology International 2018; 121: 180189. https://doi.org/10.1016/j.triboint.2018.01.062

[7] Shanbra, S., Elashab, F., Elforjanic, M. Teixeira, J. Detection of natural crack in wind turbine gearbox. Renewable Energy, 2018; 118: 172-179. https://doi.org/10.1016/j.renene.2017.10.104

[8] Zhang, Y., Lu, W., Chu, F. Planet gear fault localization for wind turbine gearbox using acoustic emission signals. Renewable Energy 2017; 109: 449-460. https://doi.org/10.1016/j.renene.2017.03.035

[9] Lapira, E., Brisset, D., ardakani, H.D., Siegel, D., Lee, J. Wind turbine performance assessment using multi-regime modelling approach. Renewable Energy 2012; 45: 8695. https://doi:10.1016/j.renene.2012.02.018 


\section{Pre-print}

[10] Magalhães, L., Martins, R., Locateli, C., Seabra, J. Influence of tooth profile and oil formulation on gear power loss. Tribology international, 36th Leeds-Lyon symposium, vol. 43(10); 2010. p. 1861-71. Special issue: multi-facets of tribology. http://dx.doi.org/10.1016/j.triboint.2009.10.001

[11] Eschmann P, Hasbargen L, Weigand K. Ball and roller bearings - theory, design, and application. John Wiley and Sons; 1985.

[12] Marques PM, Fernandes CM, Martins RC, Seabra JH. Efficiency of a gearbox lubricated with wind turbine gear oils. Tribology International 2014; 71:7-16, https://doi.org/10.1016/j.triboint.2013.10.017

[13] Lin, Y., Tu, L., Liu, H., Li, W. Fault analysis of wind turbines in China. Renewable and Sustainable Energy Reviews 2016; 55: 482-490. http://dx.doi.org/10.1016/j.rser.2015.10.149

[14] Zhou KP. Research and design of fault diagnosis system for direct-driven synchronous wind turbine [Master's thesis]. Changsha: Central South Univ.; 2010. [15] Ma HZ, Shi WJ, Han JD, Chen JN, Chen TT. Double-fed induction generator rotor fault diagnosis considering control strategies of rotor-side converters. Proc CSEE 2013;33:1-7.

[16] Li R, Gao, QS, Liu, W. Characteristics of direct-driven permanent magnet synchronous wind power generator under symmetrical three-phase short-circuit fault. Power System Technology, 2011; 35:153-8.

[17] Entezami M, Hillmansen S, Weston P, Papaelias MP. Fault detection and diagnosis within a wind turbine mechanical braking system using condition monitoring. Renewable Energy 2012; 47:175-82. https://doi.org/10.1016/j.renene.2012.04.031 [18] Rose J, Hiskens IA. Estimating wind turbine parameters and quantifying their effects on dynamic behavior. IEEE Power \& Energy Society General Meeting; Jul. 2008:1-7. https://doi.org/10.1109/PES.2008.4596862

[19] Spinato, F., Tavner, P.J., van Bussel, G.J.W., Koutoulakos, E. Reliability of wind turbine subassemblies. IET Renew Power Gen 2009; 3:387-401. http://dx.doi.org/10.1049/iet-rpg.2008.0060 


\section{Pre-print}

431 [20] Ziegler, L., Gonzalez, H., Rubert, T., Smolka, U., Melero, J. Lifetime extension of onshore wind turbines: A review covering Germany, Spain, Denmark, and the UK. Renewable and Sustainable Energy Reviews, 2018; 82:1261-1271. http://dx.doi.org/10.1016/j.rser.2017.09.100

[21] H. Arabian-Hoseynabadi, H. Oraee, P.J. Tavner. Failure Modes and Effects Analysis (FMEA) for Wind Turbines, Int. J. Electrical Power Energy System, 2010; 32(7):817-824. https://doi.org/10.1016/j.ijepes.2010.01.019

[22] RELIAWIND project. European Union's Seventh Framework Programme for RTD (FP7). http://windpower.sandia.gov/2009Reliability/PDFs/Day2-13MichaelWilkinson.pdf (accessed 22.01.2018) [23] Tavner P. Offshore Wind Turbines: Reliability, Availability and Maintenance. London: Institution of Engineering and Technology; 2012.

[24] Touret, T., Changenet, C., Ville, F., Lalmi, M., Becquerelle, S. On the use of temperature for online condition monitoring of geared systems - A review, Mechanical Systems and Signal Processing 2018; 101:197-210. http://dx.doi.org/10.1016/j.ymssp.2017.07.044

[25] Marques, P.M., Fernandes, C.M., Martins, R.C., Seabra, J.H. Power losses at low speed in a gearbox lubricated with wind turbine gear oils with special focus on churning losses. Tribology International 2013; 62:186-97. http://dx.doi.org/10.1016/j.triboint.2013.02.026.

[26] Song, Z., Zhang, Z., Jiang, Zhu, J. Wind turbine health state monitoring based on a Bayesian data-driven approach. Renewable Energy, 2018; 125:172-181. https://doi.org/10.1016/j.renene.2018.02.096

[27] Castellani, F., Astolfi, D., Sdringola, P., Proietti, S., Terzi, L. Analyzing wind turbine directional behavior: SCADA data mining techniques for efficiency and power assessment. Applied Energy, 2017; 185:1076-1086. http://dx.doi.org/10.1016/j.apenergy.2015.12.049

[28] Wind Turbine Power Performance IEC 61400-12-1, Power performance measurements according to the international guidelines, IEC 61400-12-1. 


\section{Pre-print}

[29] T. Toureta, C. Changenetb, F. Villea, M. Lalmic, S. Becquerellec. On the use of temperature for online condition monitoring of geared systems. Mechanical Systems and Signal Processing 2018; 101:197-210. http://dx.doi.org/10.1016/j.ymssp.2017.07.044 [30] Feng, Y., Qiu, Y., Crabtree, C., Long, H. Tavner, P. Monitoring Wind Turbine Gearboxes. Wind Energy 2013; 16:728-740. https://doi.org/10.1002/we.1521

[31] Salameh, J., Cauet, S., Etien, E., Sakout, A., Rambault, L. Gearbox condition monitoring in wind turbines: A review. Mechanical Systems and Signal Processing 2018; 111:251-264. https://doi.org/10.1016/j.ymssp.2018.03.052

[32] Nélias, D., Dumont, M.L., Champiot, F., Vincent, A., Flamand, L., Role of inclusions, surface roughness and operating conditions on rolling contact fatigue, Journal of Tribololgy., 1999; 121:240-250. https://doi.org/10.1115/1.2833927

[33] Littmann, W.E., Kelley, B., Anderson, W.J., Fein, R.S., Klaus, E., Sibley, L.B., Winer, W., Chemical effects of lubrication in contact fatigue - 3. load-life exponent, life scatter, and overall analysis, Journal of Lubrication Technology, ASME,1976; 98:308318. https://doi.org/10.1115/1.3452832

[34] Hostis, B., Minfraya, C., Frégonèse, M., Verdub, C., Ter-Ovanessian, B., Vachera, B., Le Mognea, T., Jarnias, F., D’Ambrose, A., Influence of lubricant formulation on rolling contact fatigue of gears - interaction of lubricant additives with fatigue cracks, Wear, 2017; 382-383: 113-122. https://doi.org/10.1016/j.wear.2017.04.025

[35] B.R. Höhn , K. Michaelis. Influence of oil temperature on gear failures. Tribology International 37, 2004; 103-109. https://doi.org/10.1016/S0301-679X(03)00047-1

[36] Cardis, A.B. Gear oil micropitting evaluation, Gear Technolology; 2000; 17: 30-35.

[37] L’Hostis, B., Minfraya, C., Frégonèse, M., Verdub, C., Ter-Ovanessian, B., Vacher, B., Le Mogne, T., Jarnias, F., D’Ambros, A. Influence of lubricant formulation on rolling contact fatigue of gears - interaction of lubricant additives with fatigue cracks, Wear, 2017; Volumes 382-383:113-122. https://doi.org/10.1016/j.wear.2017.04.025

[38] Lainé, A., Olver, A., Lekstrom, M., Shollock, B., Beveridge, T., Hua, D. The effect of a friction modifier additive on micropitting; Tribology Transactions, 2009; 52:526533. https://doi.org/10.1080/10402000902745507 


\section{Pre-print}

[39] Nutakor, C., Kłodowski, A., Sopanen, J., Mikkola, A., Pedrero, J. Planetary gear sets power loss modeling: Application to wind turbines. Tribology International, 2017; 105:42-54. http://dx.doi.org/10.1016/j.triboint.2016.09.029

[40] Leite, G., Araújo, A., Rosas, P. Prognostic techniques applied to maintenance of wind turbines: a concise and specific review. Renewable and Sustainable Energy Reviews, 2018; 81:1917-1925. http://dx.doi.org/10.1016/j.rser.2017.06.002

[41] Bangalore, P., Patriksson, M. Analysis of SCADA data for early fault detection, with application to the maintenance management of wind turbines. Renewable Energy, 2018; 115: 521-532. http://dx.doi.org/10.1016/j.renene.2017.08.073

[42] Willis, D, Niezrecki, C., Kuchma, D., Hines, E., Arwade, S., Barthelmie, R., DiPaola, M., Drane, P., Hansen, C., Inalpolat, M., Mack, J., Myers, A., Rotea,M. Wind energy research: State-of-the-art and future research directions, Renewable Energy, 2018; 125:133-154. https://doi.org/10.1016/j.renene.2018.02.049

2

3

4

05




\section{Pre-print}

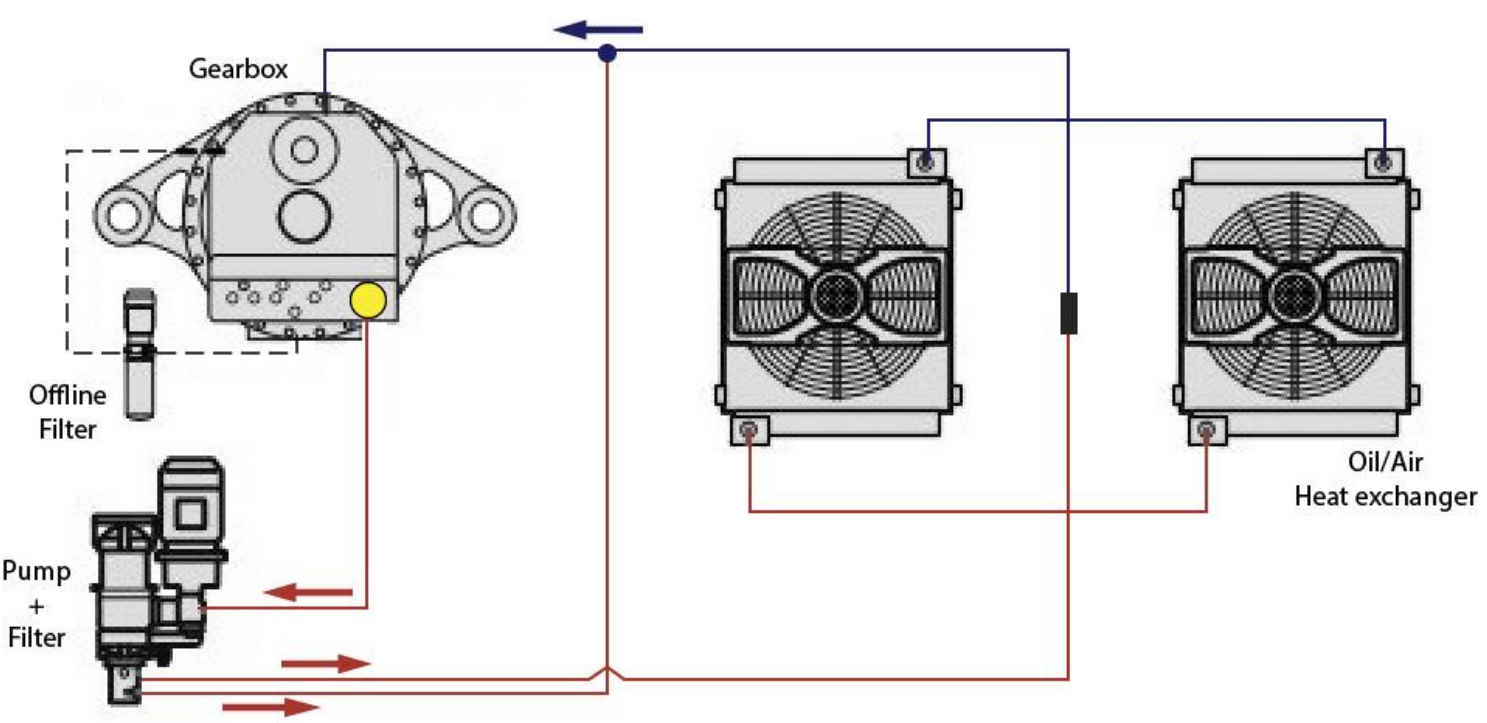

Figure 1. Gearbox cooling circuit. The gearbox is provided with a combined splash / circulatory lubricating system. The cooled and filtered oil is fed to the gearbox through a distributor (blue point) which distributes it to the bearings through internal pipes and the borings (blue arrow). The oil pressure is approx. $2.5-3$ bar at an oil sump temperature of $60^{\circ} \mathrm{C}$. The gear case of the helical gearbox is fitted, below the oil level, with the screw-in heaters with replaceable heating rods (yellow circle on gearbox). The heaters must be switched on when the oil sump temperature drops below $+5^{\circ} \mathrm{C}$ (red lines and arrows), cooling the oil. The switch-off point lies between $+10^{\circ} \mathrm{C}$ and $+15^{\circ} \mathrm{C}$. Monitoring is ensured by the above mentioned resistance thermometers. 


\section{Pre-print}
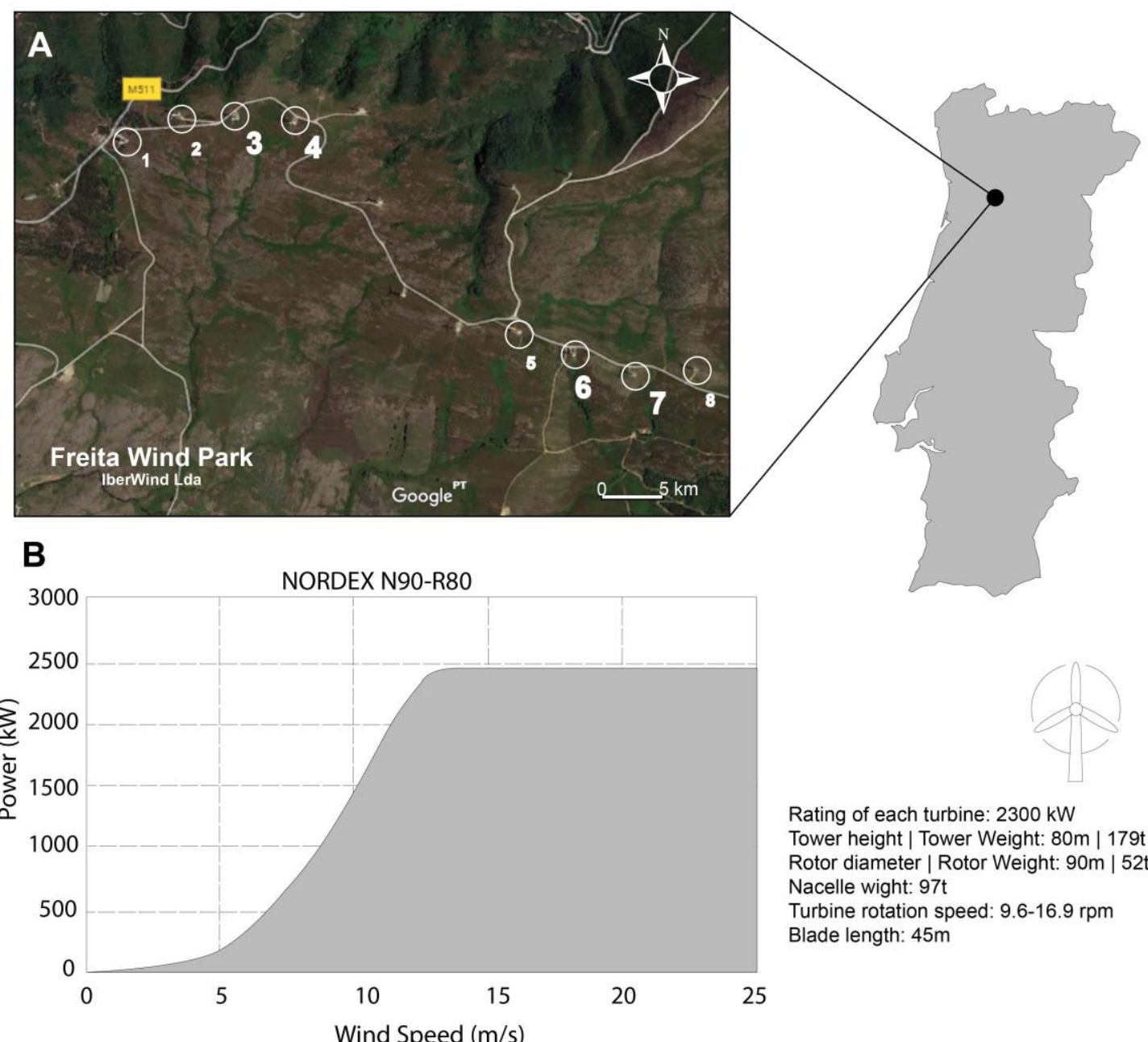

Rating of each turbine: $2300 \mathrm{~kW}$

Tower height | Tower Weight: 80m | 179t

Rotor diameter | Rotor Weight: $90 \mathrm{~m}$ | $52 \mathrm{t}$ Nacelle wight: $97 \mathrm{t}$

Turbine rotation speed: $9.6-16.9 \mathrm{rpm}$

Blade length: $45 \mathrm{~m}$ 


\section{Pre-print}

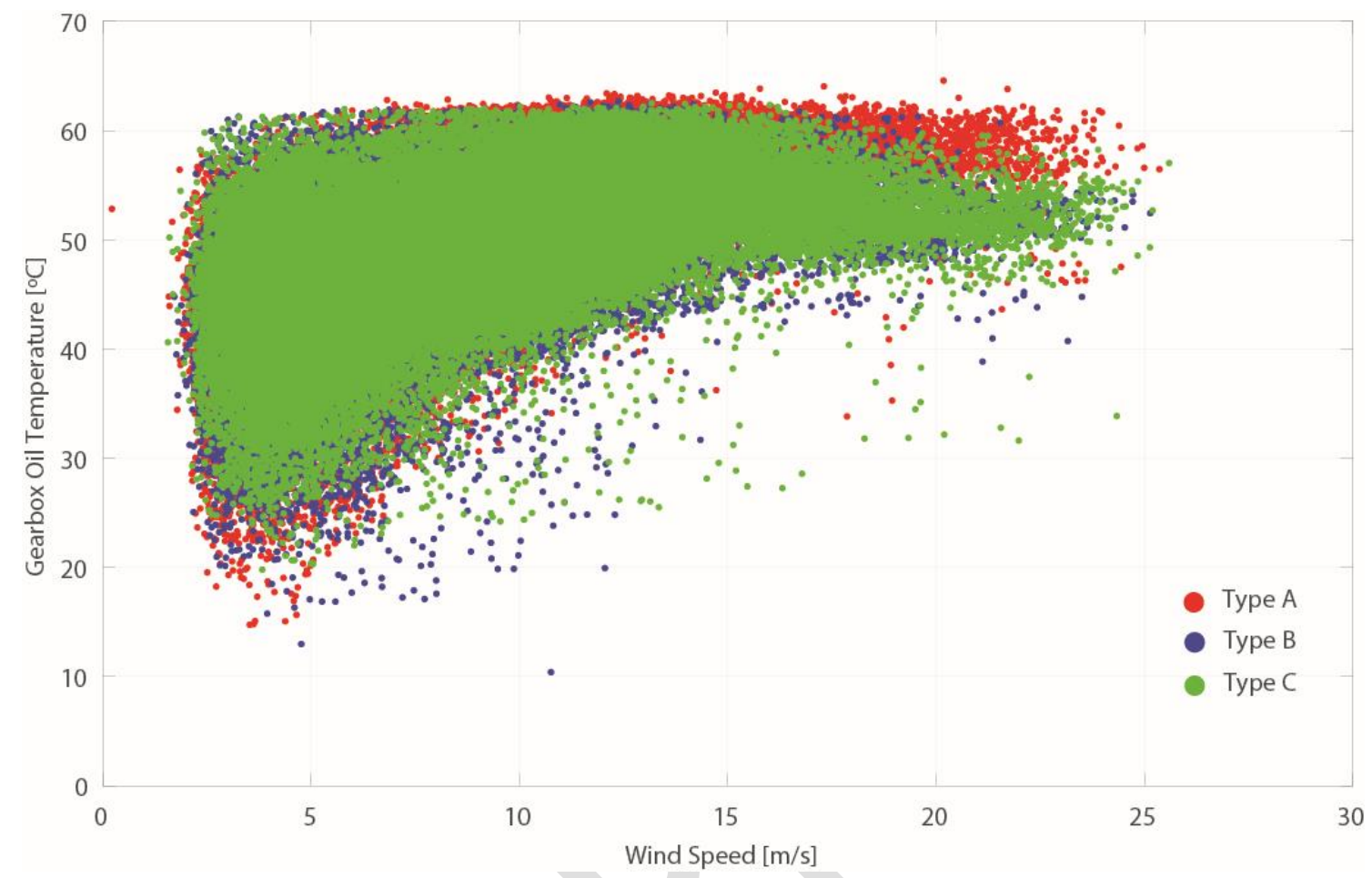

Figure 2. (A) Freita' Wind Park, Arouca (Portugal). On the image in white are represented the four turbines operating since 2006 and without gearboxes replacements; (B) Power curve of the NORDEX N90-R80 turbines and characteristics.

Figure 3. Example of the pre filter raw data from the SCADA system showing the relation between the gearbox temperature $\left({ }^{\circ} \mathrm{C}\right)$ and wind speed $(\mathrm{m} / \mathrm{s})$ for different oil types. Example is from the wind turbine 3 of the Freita' Wind Park, Arouca (Portugal). 


\section{Pre-print}
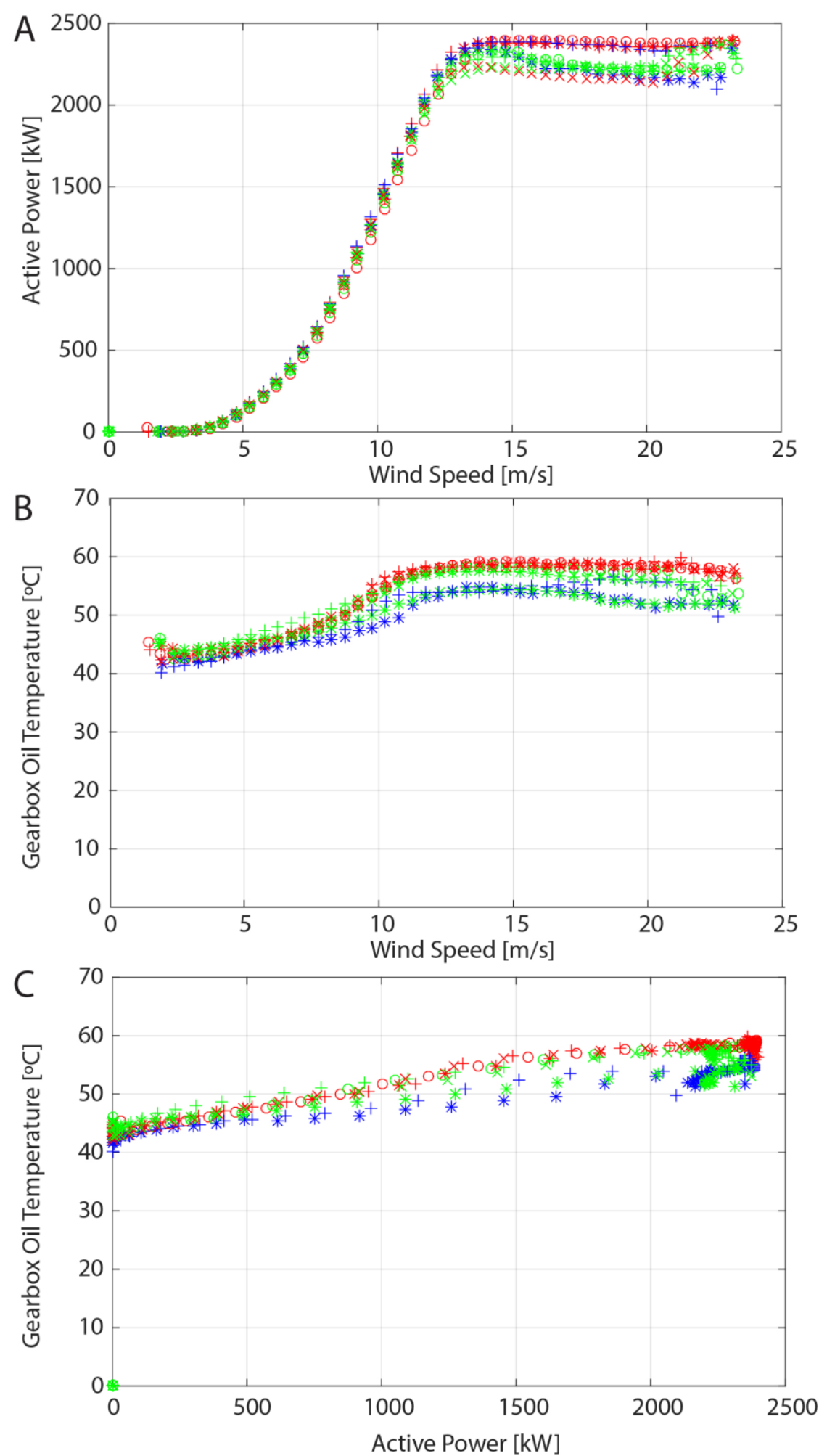

Type $\mathrm{A}$ Type $\mathrm{B}$ Type C

\section{Wtg 3 * $W \operatorname{tg} 4+W \operatorname{tg} 6 \quad \times W \operatorname{tg} 7$}

Figure 4. Bin method results for the four analysed wind turbine gearboxes (Wtg) and for the three different oil types: (A) active power curves as a function of wind speed; (B) oil temperature inside gearboxes as a function of wind speed; (C) oil temperature inside gearboxes as a function of active power production. 


\section{Pre-print}
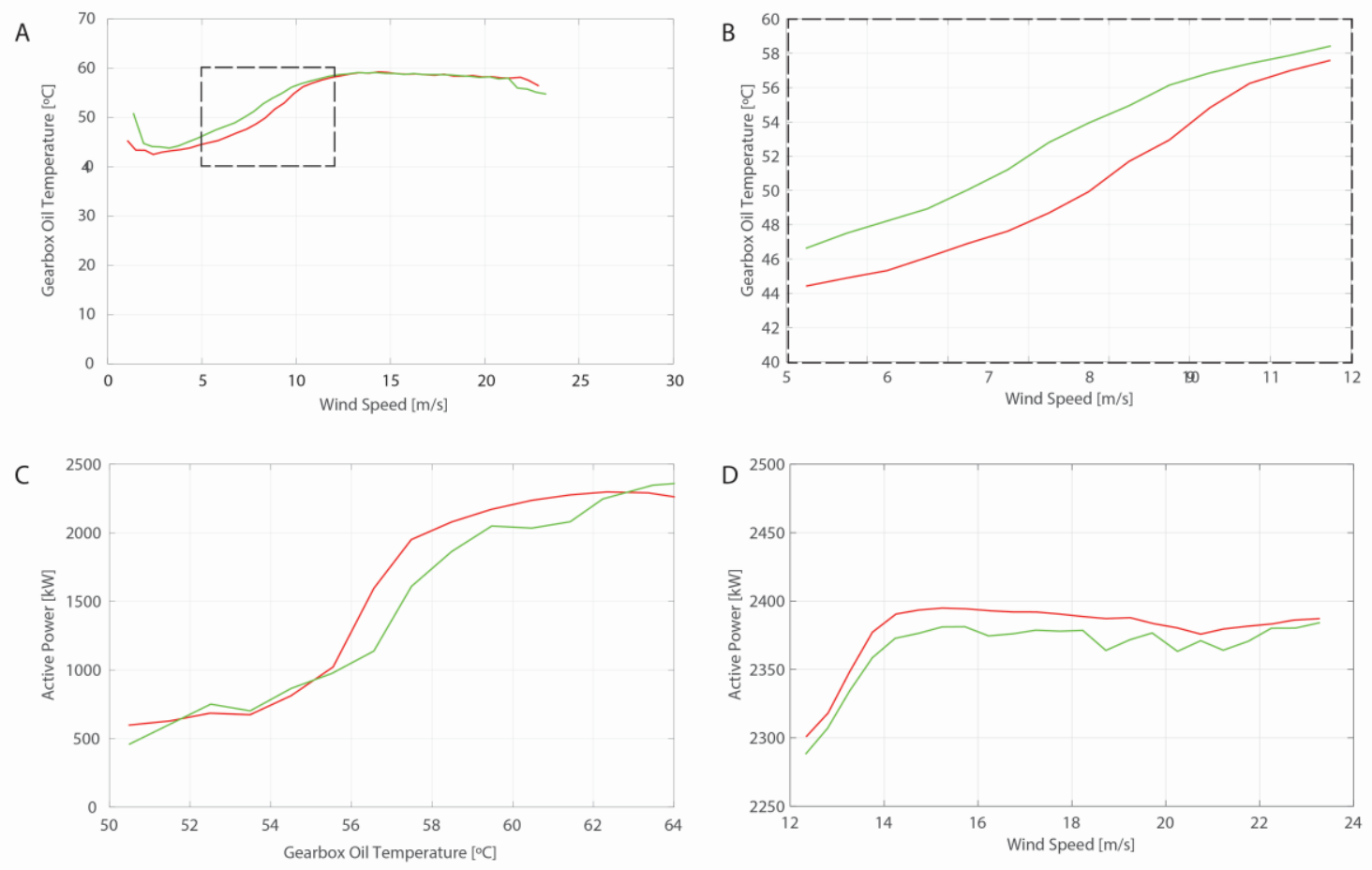

539 Figure 5. (A) Relation between gearbox oil temperature and wind speed velocity after oil replacement from type $\mathrm{A}$ to $\mathrm{C}$ on turbine 3; (B) zoom in to the velocity range where most measurements were registered and where the highest temperature differences were observed; (C) active power produced in the higher temperature range, showing significant differences at an oil temperature of $58^{\circ} \mathrm{C}$; and (D) differences of wind energy production within the range of speeds between 12 and $15 \mathrm{~m} / \mathrm{s}$, registering the largest differences $(\sim 20 \mathrm{~kW})$. 


\section{Pre-print}

A

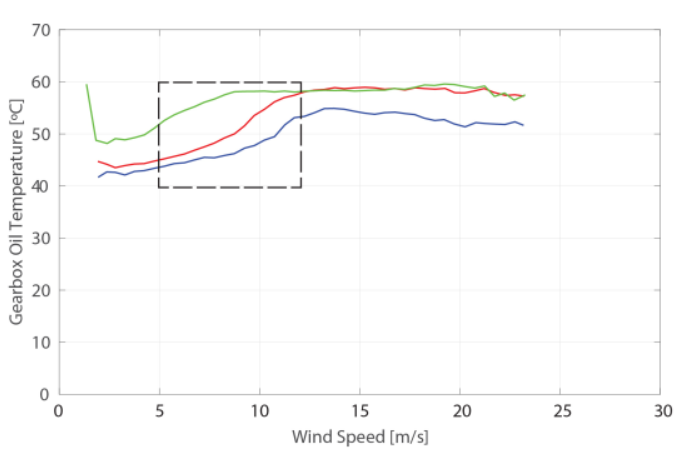

C

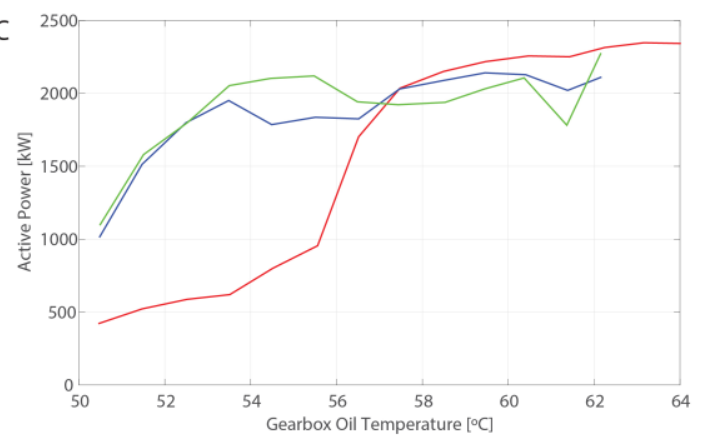

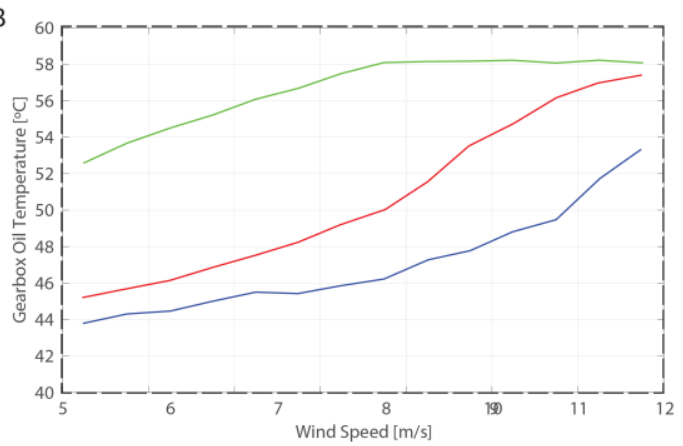

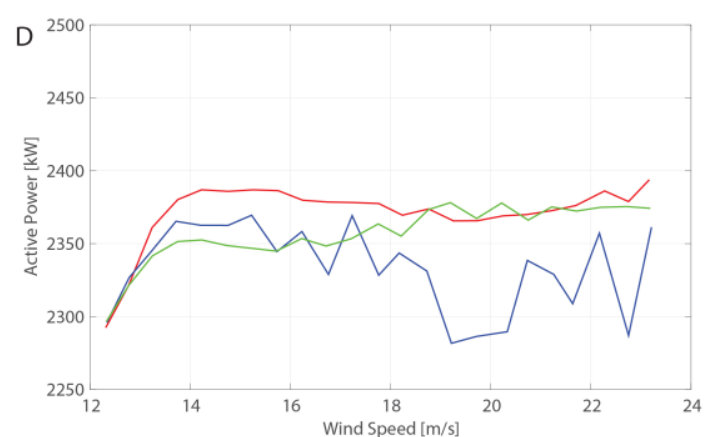

Type B Type C

Figure 6. (A) Relation between gearbox oil temperature and wind speed velocity after oil replacements on turbine 4 which experienced the three different oils types; (B) zoom in to the velocity range where most measurements were registered and where the highest temperature differences were observed; (C) active power produced in the higher temperature range, showing that the largest production differences are recorded in the temperature range between $52^{\circ} \mathrm{C}$ and $56^{\circ} \mathrm{C}$; and (D) differences of wind energy production within the range of speeds between 12 and $24 \mathrm{~m} / \mathrm{s}$, where it is observed the poorest performance when using oil B. 


\section{Pre-print}
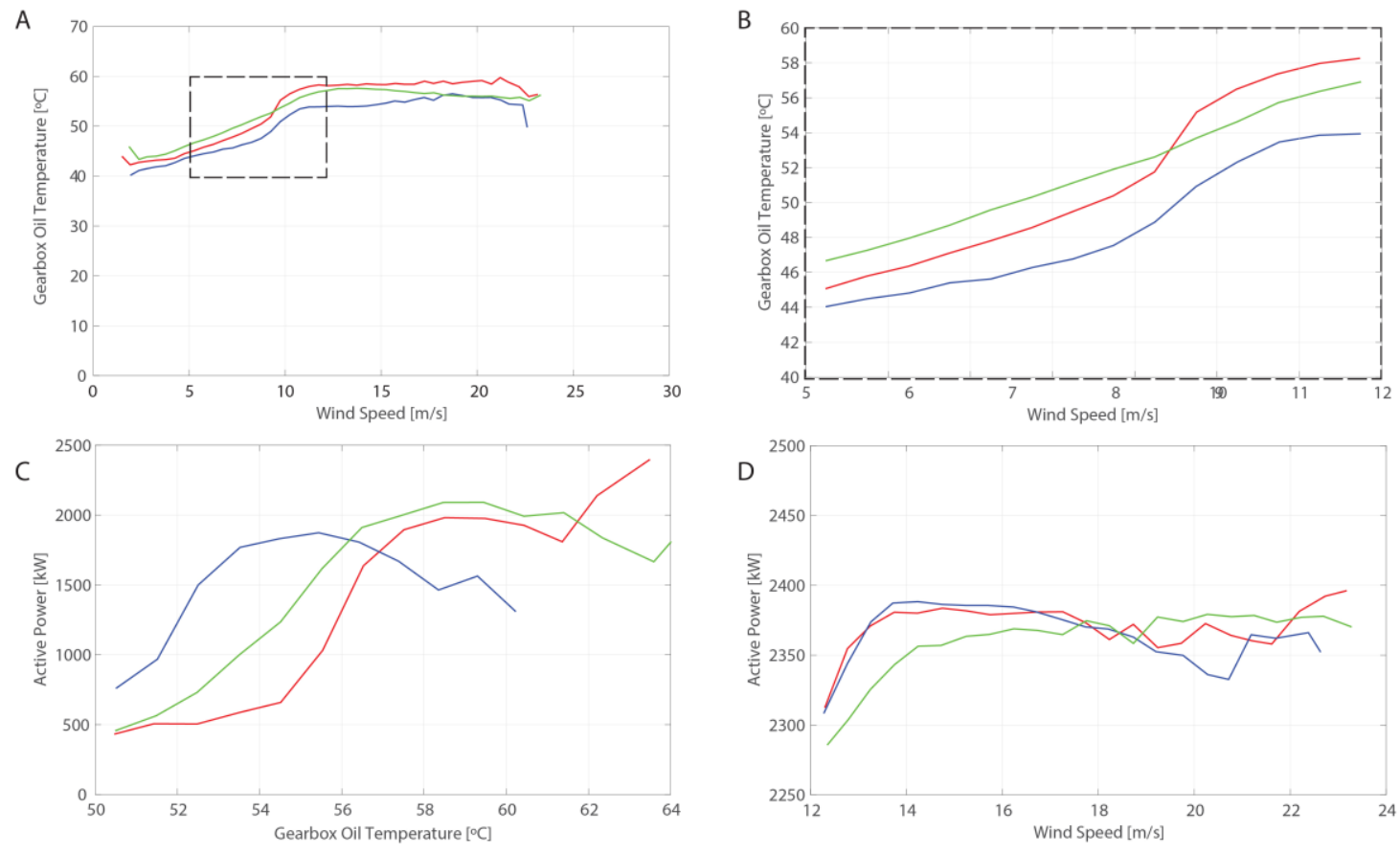

Type B Type C

Figure 7. (A) Relation between gearbox oil temperature and wind speed velocity after oil replacements on turbine 6 which experienced the three different oils types; (B) zoom in to the velocity range where most measurements were registered, where is observed that type A presents the higher temperatures inside gearbox for velocities over $10 \mathrm{~m} / \mathrm{s}$ i.e. the beginning of nominal wind speed; (C) active power produced in the higher temperature range, showing that the largest production differences are recorded in the temperature range between $52^{\circ} \mathrm{C}$ and $56^{\circ} \mathrm{C}$; and (D) differences of wind energy production within the range of speeds between 12 and $24 \mathrm{~m} / \mathrm{s}$, where it is observed again the poorest performance when using oil B. 


\section{Pre-print}

A

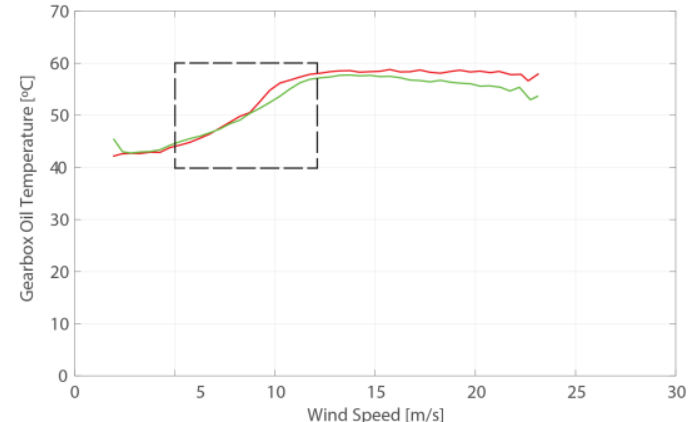

C

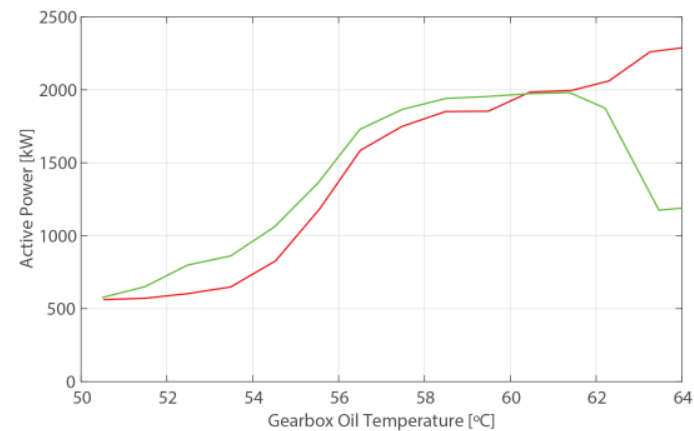

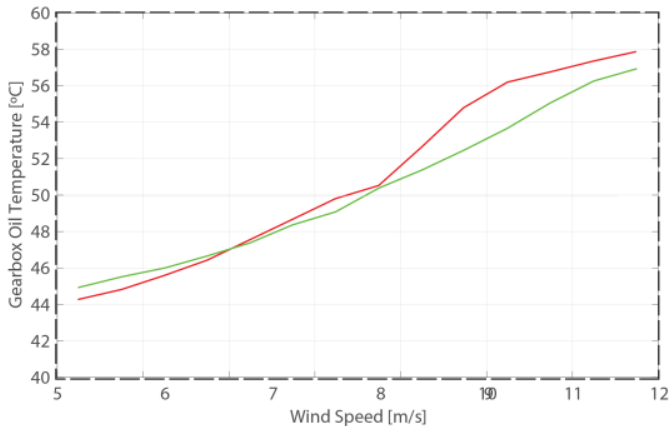

D

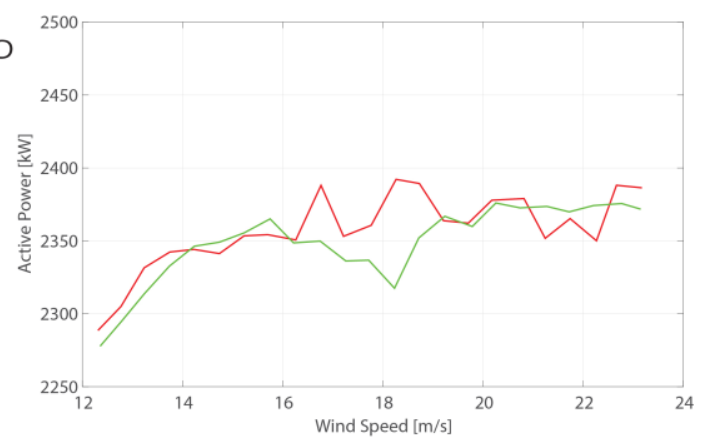

56

- Type A Type C

Figure 8. (A) Relation between gearbox oil temperature and wind speed velocity after oil replacements on turbine 7 which experienced two different oils types; (B) zoom in to the velocity range where most measurements were registered. In this case temperature differences are only noticeable over $9 \mathrm{~m} / \mathrm{s}$; (C) the largest differences on active power production occur between $52^{\circ} \mathrm{C}$ and $57^{\circ} \mathrm{C}$ i.e. before the exchanger fans are turned on; and (D) overall negligible differences of wind energy production within the range of speeds between 12 and $24 \mathrm{~m} / \mathrm{s}$, registering a maximum of plus $80 \mathrm{~kW}$ using type A oil at $18.2 \mathrm{~m} / \mathrm{s}$. 


\section{Pre-print}

\section{TABLE CAPTIONS}

Table 1. Types of oil and characteristics used on the NORDEX N90 gearboxes.

\begin{tabular}{|c|c|c|c|}
\hline & $\mathbf{A}$ & B & $\mathbf{C}$ \\
\hline Type & Mineral (MINR) & \multicolumn{2}{|c|}{ Synthetic polyalphaolefin (PAO) } \\
\hline ISO Viscosity Grade & 320 & 320 & 320 \\
\hline Viscosity, ASTM D 445, cSt @ $40^{\circ} \mathrm{C}$ & 320 & 320 & 325 \\
\hline $\begin{array}{c}\text { Viscosity, ASTM D 445, cSt @ } \\
{100^{\circ} \mathrm{C}}^{\text {A }}\end{array}$ & 24.1 & 35.1 & 34.9 \\
\hline Viscosity Index, ASTM D 2270 & 96 & 155 & 152 \\
\hline Density@15 C & 0.903 & 0.943 & 0.854 \\
\hline Flash Point $\left({ }^{\circ} \mathrm{C}\right)$ & 268 & 280 & 250 \\
\hline Fusion Point $\left({ }^{\circ} \mathrm{C}\right)$ & -18 & -33 & -33 \\
\hline \multicolumn{4}{|l|}{ Chemical Properties } \\
\hline Calcium (Ca mg/kg) & 7 & 5 & 1511 \\
\hline Magnesium (Mg mg/kg) & 0 & 0 & 3 \\
\hline Boron (B mg/kg) & 0 & 0 & 0 \\
\hline Zinc (Zn mg/kg) & 51 & 29 & 4 \\
\hline Phosphorus (P mg/kg) & 203 & 200 & 311 \\
\hline Barium (Ba mg/kg) & 0 & 0 & 0 \\
\hline Molybdenum (Mo mg/kg) & 2 & 0 & 808 \\
\hline \multirow[t]{2}{*}{ Sulphur (S $\mathrm{mg} / \mathrm{kg})$} & 13258 & 3013 & 2586 \\
\hline & A & $\mathrm{B}$ & $\mathrm{C}$ \\
\hline Type & Mineral (MINR) & Synthetic & fin $(\mathrm{PAO})$ \\
\hline ISO Viscosity Grade & 320 & 320 & 320 \\
\hline Viscosity, ASTM D 445, cSt @ 40C & 320 & 320 & 325 \\
\hline $\begin{array}{c}\text { Viscosity, } \\
{ }_{100^{\circ} \mathrm{C}} \mathrm{AST}\end{array}$ & 24.1 & 35.1 & 34.9 \\
\hline Viscosity Index, ASTM D 2270 & 96 & 155 & 152 \\
\hline Density@15 ${ }^{\circ} \mathrm{C}$ & 0.903 & 0.943 & 0.854 \\
\hline Flash Point $\left({ }^{\circ} \mathrm{C}\right)$ & 268 & 280 & 250 \\
\hline Fusion Point $\left({ }^{\circ} \mathrm{C}\right)$ & -18 & -33 & -33 \\
\hline \multicolumn{4}{|l|}{ Chemical Properties } \\
\hline Calcium (Ca mg/kg) & 7 & 5 & 1511 \\
\hline Magnesium (Mg mg/kg) & 0 & 0 & 3 \\
\hline Boron (B mg/kg) & 0 & 0 & 0 \\
\hline Zinc $(\mathrm{Zn} \mathrm{mg/kg)}$ & 51 & 29 & 4 \\
\hline Phosphorus (P mg/kg) & 203 & 200 & 311 \\
\hline Barium (Ba mg/kg) & 0 & 0 & 0 \\
\hline Molybdenum (Mo mg/kg) & 2 & 0 & 808 \\
\hline Sulphur (S mg/kg) & 13258 & 3013 & 2586 \\
\hline
\end{tabular}

Table 2. Wind turbine gearbox (WTG) exchange dates and used oils types on the NORDEX N90 gearboxes.

\begin{tabular}{cccc}
\hline WTG Number & Type A & Type B & Type C \\
\hline Wtg\#3 & $05 / 04 / 2011$ & & $24 / 05 / 2013$ \\
\hline Wtg\#4 & $10 / 05 / 2011$ & $23 / 01 / 2012$ & $30 / 01 / 2013$ \\
\hline Wtg\#6 & $05 / 04 / 2011$ & $23 / 01 / 2012$ & $30 / 01 / 2013$ \\
\hline Wtg\#7 & $02 / 04 / 2012$ & & $19 / 03 / 2013$ \\
\hline
\end{tabular}




\section{Pre-print}

Table 3. Sampling results on oil viscosity for the different turbine gearboxes.

\begin{tabular}{|c|c|c|c|c|c|c|c|c|c|c|}
\hline Wind Gearbox (\#Wtg) & \#V & $\operatorname{tg} 3$ & & \#Wtg4 & & & \#Wtg6 & & & \\
\hline Oil Type & A & $\mathrm{C}$ & A & $\mathrm{B}$ & $\mathrm{C}$ & A & $\mathrm{B}$ & $\mathrm{C}$ & A & $\mathrm{C}$ \\
\hline Viscosity, ASTM D 445, cSt @ 40 C & 315.96 & 313.16 & 314.28 & 306.93 & 307.78 & 309.58 & 308.85 & 304.77 & 316.17 & 312.48 \\
\hline Viscosity, ASTM D 445, cSt @ $100^{\circ} \mathrm{C}$ & 23.54 & 32.00 & 23.56 & 32.14 & 32.51 & 23.50 & 31.38 & 32.78 & 23.60 & 34.22 \\
\hline Viscosity Index, ASTM D 2270 & 94 & 142 & 93 & 145 & 147 & 95 & 140 & 149 & 94 & 154 \\
\hline
\end{tabular}

149 


\section{Pre-print}

\section{Highlights}

- Analysis of real data from wind farms monitored and controlled by SCADA system

- Relations established between lubricant selection and the active power production

- Direct relation observed between oil characteristics and energy efficiency

- Gearboxes working with oils of similar nature result in differences on performance

- Noted oil degradation as a function of temperature increase, affecting production 